\title{
Storage Stability of Garlic Fortified Chicken Bites
}

\author{
Kanza Aziz Awan ${ }^{1}$, Masood Sadiq Butt ${ }^{1}$, Iahtisham-U1-Haq ${ }^{1}$, Faiza Ashfaq ${ }^{1}$ and Hafiz Ansar Rasul Suleria ${ }^{2 *}$ \\ ${ }^{1}$ National Institute of Food Science and Technology, Faculty of Food, Nutrition and Home Sciences, University of Agriculture, Faisalabad, Pakistan \\ ${ }^{2} U Q$ School of Medicine, University of Queensland, Australia
}

\author{
Correspondence to: \\ Hafiz Ansar Rasul Suleria \\ Honorary Fellow UQ School of Medicine \\ The University of Queensland \\ Brisbane QLD 4072, Australia \\ E-mail: hafiz.suleria@uqconnect.edu.au
}

Received: May 02, 2017

Accepted: June 15, 2017

Published: June 19, 2017

Citation: Awan KA, Butt MS, Haq IU, Ashfaq F, Suleria HAR. 2017. Storage Stability of Garlic Fortified Chicken Bites. J Food Chem Nanotechnol 3(2): 80-85.

Copyright: (C) 2017 Awan et al. This is an Open Access article distributed under the terms of the Creative Commons Attribution 4.0 International License (CC-BY) (http://creativecommons. org/licenses/by/4.0/) which permits commercial use, including reproduction, adaptation, and distribution of the article provided the original author and source are credited.

Published by United Scientific Group

\begin{abstract}
The tremendous demand of functional food, nutraceuticals and fortified products has urged the food scientists and technologist to come up with novel fortified foods having health promoting benefits, sensorial acceptability and better shelf life. Garlic (Allium sativum) is a promising source of bioactive compounds, especially allicin. The current study evaluates storage stability and sensorial attributes of garlic supplemented chicken bites. The color tonality of fortified products indicated slight reduction in product lightness $\left(\mathrm{L}^{*}\right)$ and redness $\left(a^{*}\right)$ for 28 days storage whereas gradual increase in the yellowness $\left(b^{*}\right)$ of chicken bites. Moreover, the texture hardness for chicken bites in $\mathrm{T}_{1}$ (chicken bites $3 \%$ conventional garlic extract) was maximum $0.9 \pm 0.02 \mathrm{~kg}$ force in contrast to $\mathrm{T}_{2}$ (chicken bites containing $0.1 \%$ supercritical garlic extract) $0.8 \pm 0.02 \mathrm{~kg}$ force. Garlic chicken bites containing supercritical garlic extract showed highest phenolic content $(73.2 \pm 3.7 \mathrm{mg} \mathrm{GAE} / 100 \mathrm{~g})$ as compared to control (63.8 \pm $2.7 \mathrm{mg}$ GAE$/ 100 \mathrm{~g})$. Moreover, total phenolics were decreased to in control as compared to $T_{0}$ and $T_{2}$, during storage. Our research study reveals that garlic fortification improves the stability and sensory attributes of chicken bites.
\end{abstract}

\section{Keywords}

Garlic extracts, Chicken bites, Total phenolic content, Storage stability, Sensory attributes

\section{Introduction}

Fried foods are generally liked by all age groups. Fried chicken is one of the most commonly available fast food item particularly in Pakistan [1]. Food perception are characterized by their color and crispy texture. Mostly these fried foods are cooked rapidly and turn into an appealing golden brown color, rich flavor and crispy texture depending upon the frying time and temperature. These fried foods savored by the consumers can became a good vehicle to deliver healthy ingredients to the populations [2].

Garlic is a rich source of polyphenolic compounds and essential to regulate human health. An active constituent of garlic named as "allicin" is produced during processing or cutting action. Number of scientific investigations have proven the health promoting perspectives of allicin [3]. Moreover, researchers and health care professionals are also focusing on the consumption of tailored and designed foods for its specific utilization. Being an important culinary ingredient, garlic and its preparations are widely used for improving the flavor profile of continental dishes [4]. However, its use as recuperative agent is still 
limited and the biologically active allicin in freshly sliced clove is often degraded at high temperature cooking [5, 6]. Allicin content can be modified in commercial preparations for better bioavailability of the active ingredient. Garlic preparations include essential oil, oil macerate, powder extract etc. can be utilized in the development of several nutraceutical and functional food products [7].

Due to the complex chemical profiling of garlic and its health protective effects, it can be employed in the manufacturing of various garlic based formulations. The most common form of garlic consumed globally is the raw garlic homogenate because of abundance of allicin in innate form. Apart from this, various garlic supplements are also present in market and are popular especially for the garlic lovers [8]. Garlic oil is usually obtained using steam distillation technique and its yield ranges about $2.5-3.0 \mathrm{~g} / \mathrm{kg}$ of fresh garlic. In garlic oil, diallyl sulfide (DAS), diallyl disulfide (DADS), and diallyl trisulfide (DATS), differ in number of sulfur atoms. These sulfides are abundant in garlic oil $[9,10]$.

Currently, garlic and onion homogenate are used in different functional foods to prevent different diseases especially for the prevention of oxidative damages [11]. Garlic addition, impart the sulfurous compounds that increase the volatiles and improve irradiated raw beef significantly [11]. Garlic addition also masked the aroma, normally less than $0.01 \%$ garlic is required to prevent or mask the irradiation aroma in irradiated raw ground beef [12].

Different garlic preparations are added in different commercial products for various purposes. "Garlic" as a functional and nutraceutical product play an important role in disease prevention [13]. However, it can also act as additive in various product preparations and enhance the shelf life of these product by reducing the oxidative damage and by increasing the antioxidant potential $[14,15]$. The present study was aimed to improve the antioxidant potential and physicochemical attributes of chicken bites by the additional/ fortification of garlic extracts.

\section{Materials and Methods}

\section{Procurement of raw materials}

Garlic (white in color - variety), chicken mince, spices and bread crumbs were procured from the local market. The reagents (analytical and HPLC grade) and standards were purchased from Merck (Merck KGaA, Darmstadt, Germany) and Sigma-Aldrich (Sigma-Aldrich Tokyo, Japan).

\section{Preparation of conventional and supercritical extracts}

Garlic extract using conventional solvent extraction (CSE) was obtained following the protocols of [16] using aqueous methanol $(50 \% \mathrm{v} / \mathrm{v})$. The extracts were evaporated till dry. Whereas, supercritical fluid extract (SFE) was obtained using $\mathrm{CO}_{2}$ at 5800 psi pressure and $50^{\circ} \mathrm{C}$ of temperature [17].

\section{Preparation of garlic chicken bites}

Garlic chicken bites were prepared using chicken mince, chili flakes, black pepper powder, ground spices, cumin seed, green chilies, coriander leaves, respective garlic extracts, egg, bread crumbs and corn flour. According to the treatments mentioned in Table $1, \mathrm{~T}_{1}$ was formulated to have $3 \%$ garlic extract (CSE), while $\mathrm{T}_{2}$ had $0.1 \%$ of garlic extract (SFE). A control sample without garlic extract was also prepared for comparison purposes.

Chicken was mixed with all mentioned spices and converted into bites shape $(5 \times 3 \times 1 \mathrm{~cm}$ each), coated with bread crumbs and frozen at $-4{ }^{\circ} \mathrm{C}$ for further analysis. The frozen samples were fried at $0,7,14$ and $28^{\text {th }}$ day interval using a household fryer and evaluated for their physicochemical and sensorial characteristics.

Table 1: Treatments for chicken bites.

\begin{tabular}{|l|l|}
\hline Treatments & Chicken bites \\
\hline $\mathbf{T}_{\mathbf{0}}$ & Control \\
\hline $\mathbf{T}_{1}$ & Chicken bites fortified with garlic extract (CSE) (3\%) \\
\hline $\mathbf{T}_{2}$ & Chicken bites fortified with garlic extract (SFE) (0.1\%) \\
\hline $\begin{array}{l}\text { CSE= Conventional Solvent Extract } \\
\text { SFE= Supercritical Fluid Extract }\end{array}$ \\
\hline
\end{tabular}

\section{Physicochemical analysis}

Color: The product surface color, $L^{*}$ (lightness), a* (-a greenness; $+\mathrm{a}$ redness), and $\mathrm{b}^{*}$ ( $-\mathrm{b}$ blueness; $+\mathrm{b}$ yellowness) were measured using CIE-Lab Color Meter (CIELAB SPACE, Color Tech-PCM, USA). The samples were placed in a transparent petri dish and positioned directly on the light path to measure the color parameter values of $\mathrm{L}^{*}, \mathrm{a}^{*}$ and $\mathrm{b}^{*}$. Color changes were also obtained using first order reaction equation according to method illustrated by Ngadi et al. [18].

Texture: The triple beam snap (three-point break) technique of Texture Analyzer(TA-HDi, Stable Microsystems, UK) was used for measuring the textural attribute of prepared product. The force required to break individual product was noted and average values were calculated according to the described protocol [19].

\section{Total phenolic content}

Total phenolic contents of chicken garlic bites were quantified by following the protocols of Asimi et al. [20]. Different aliquots of known concentration of gallic acid were taken as standard. Total polyphenols were calculated and values were expressed as gallic acid equivalent (mg GAE/100 g).

\section{Experimental design and statistical methods}

All experiments were performed in triplicates. The obtained data in this study were subjected to statistical modeling applying the two-factor factorial under completely randomized design (CRD) at the level of significance of 5\% using Statistix version 8.1 (Analytical Software, Tallahassee, FL, USA). Furthermore, the means were also interpreted and recorded as Mean \pm S.D. [21]. 


\section{Results and Discussion}

\section{Physicochemical attributes of garlic chicken bites}

Color: Color is one of the major concerns in assessing consumer perception, quality aspects and acceptability of any food product. CIELAB color system was used to carry out color estimation for chicken bites. The traits analyzed included $L^{*}, a^{*}$ and $b^{*}$ values where $L^{*}$ depicts brightness, $a^{*}$ shows greenish to reddish tonality, whilst $b^{*}$ indicates bluish to yellowish color. The means for $\mathrm{L}^{*}$ values (Table 2) for control $\left(\mathrm{T}_{0}\right)$, garlic extract $(\mathrm{CSE})\left(\mathrm{T}_{1}\right)$ and garlic extract $(\mathrm{SFE})\left(\mathrm{T}_{2}\right)$ garlic chicken bites, showed highest value for $\mathrm{T}_{0}(39.5 \pm 1.1)$ followed by $\mathrm{T}_{2}(39.3 \pm 1.1)$ and $\mathrm{T}_{1}(38.5 \pm 1.1)$. The storage period showed momentous reduction in $\mathrm{L}^{*}$ value from $39.6 \pm$ 1.1 to $38.5 \pm 1.1$.

Regarding the trait, $\mathrm{a}^{*}$ (Table 2), values for products increased towards yellow with the addition of garlic. $\mathrm{T}_{0}, \mathrm{~T}_{1}$ and $\mathrm{T}_{2}$ showed mean $\mathrm{a}^{*}$ values of $20.1 \pm 0.6,20.3 \pm 0.6$ and $20 \pm 0.6$, correspondingly. During storage of chicken garlic bites, $a^{*}$ values showed a decline from $20.5 \pm 0.6$ to $19.7 \pm 0.5$. Moreover, means for $b^{*}$ value showed a marked difference as a function of three treatments; $40 \pm 1.2$ was recorded in $\mathrm{T}_{0}$, $47.7 \pm 1.4$ in $\mathrm{T}_{1}$ and $45 \pm 1.3$ in $\mathrm{T}_{2}$. However, during storage, gradual increase in $b^{*}$ value was recorded although the changes were momentous.

Addition of garlic in chicken bites resulted in significant increase in chroma value as $44.7 \pm 1.3$ for $T_{0}, 51.9 \pm 1.5$ for $T_{1}$ and $49.2 \pm 1.4$ for $T_{2}$. Storage interval led to significant decline from $49.7 \pm 1.4$ to $47.5 \pm 1.4$. Moreover, means for "hue angle" revealed that addition of garlic affected this character momentously i.e. $63.3 \pm 1.9,66.8 \pm 2.1$ and $66 \pm 1.9$ for $\mathrm{T}_{0}$, $\mathrm{T}_{1}$ and $\mathrm{T}_{2}$, respectively. However, 28 days storage interval did not show significant effect on hue angle of chicken garlic bite. Thus, non-momentous variations are observed initially during storage and some-what substantial at the end of storage trial.

Chicken bites are minced meat product, formulated by combining different ingredients, coating and frying them [22]. Commercially, the closely related product to bites is nuggets, which is having same attributes and similar recipe. Our results are comparable with the findings of Banerjee et al. [23] who reported the antioxidant effects of broccoli extract in nuggets. Results revealed non-substantial differences in the redness, yellowness and hue values amongst all the prepared nuggets treatments. This could be attributed to the slightly greyish color of the broccoli powder extract. With respect to hedonic characteristics the study has been published previously indicating higher overall acceptability scores for garlic extract (SFE) enriched chicken bites [24]. Similarly, another research was conducted on chicken patties which are like nuggets as minced meat is used inside the patties as filling with a harder outer covering. According to Naveena et al. [25] incorporation of pomegranate rind powder extract results in slightly dark chicken patties.

Frying temperatures have significant impact on the color of nuggets. Ngadi et al. [18] observed L* value of the fried chicken nuggets decreased with frying time. The reduction in
Table 2: Effect of treatments and storage on $\mathrm{L}^{*}, \mathrm{a}^{*}, \mathrm{~b}^{*}$, chroma and hue angle of garlic chicken bites.

\begin{tabular}{|c|c|c|c|c|c|}
\hline \multirow{2}{*}{ Traits } & \multirow{2}{*}{$\begin{array}{l}\text { Storage } \\
\text { (days) }\end{array}$} & \multicolumn{3}{|c|}{ Treatments } & \multirow{2}{*}{ Means } \\
\hline & & $T_{0}$ & $\mathrm{~T}_{1}$ & $\mathrm{~T}_{2}$ & \\
\hline \multirow{6}{*}{$L^{*}$} & 0 & $40 \pm 1.2$ & $38.9 \pm 1.1$ & $39.9 \pm 1.2$ & $39.6 \pm 1.1^{a}$ \\
\hline & 7 & $39.8 \pm 1.1$ & $38.8 \pm 1.1$ & $39.7 \pm 1.1$ & $39.4 \pm 1.1^{\mathrm{a}}$ \\
\hline & 14 & $39.5 \pm 1.1$ & $38.6 \pm 1.1$ & $39.4 \pm 1.1$ & $39.2 \pm 1.1^{a}$ \\
\hline & 21 & $39.3 \pm 1.1$ & $38.3 \pm 1.1$ & $39.1 \pm 1.1$ & $38.9 \pm 1.1^{\mathrm{ab}}$ \\
\hline & 28 & $38.8 \pm 1.1$ & $37.9 \pm 1.1$ & $38.7 \pm 1.1$ & $38.5 \pm 1.1^{\mathrm{ab}}$ \\
\hline & Means & $39.5 \pm 1.1^{a}$ & $38.5 \pm 1.1^{\mathrm{ab}}$ & $39.3 \pm 1.1^{a}$ & \\
\hline \multirow{6}{*}{$a^{*}$} & 0 & $20.5 \pm 0.6$ & $20.7 \pm 0.6$ & $20.3 \pm 0.5$ & $20.5 \pm 0.6^{a}$ \\
\hline & 7 & $20.3 \pm 0.6$ & $20.6 \pm 0.6$ & $20.1 \pm 0.5$ & $20.3 \pm 0.5^{\mathrm{a}}$ \\
\hline & 14 & $20.1 \pm 0.6$ & $20.4 \pm 0.6$ & $20 \pm 0.6$ & $20.1 \pm 0.6^{\mathrm{ab}}$ \\
\hline & 21 & $19.9 \pm 0.5$ & $20.2 \pm 0.6$ & $19.8 \pm 0.5$ & $20 \pm 0.5^{\mathrm{ab}}$ \\
\hline & 28 & $19.6 \pm 0.5$ & $19.9 \pm 0.5$ & $19.6 \pm 0.6$ & $19.7 \pm 0.5^{b}$ \\
\hline & Means & $20.1 \pm 0.6^{\mathrm{a}}$ & $20.3 \pm 0.6^{a}$ & $20 \pm 0.6^{\mathrm{ab}}$ & \\
\hline \multirow{6}{*}{$b^{*}$} & 0 & $41 \pm 1.2$ & $48.7 \pm 1.4$ & $45.9 \pm 1.3$ & $45.2 \pm 1.3^{\mathrm{a}}$ \\
\hline & 7 & $40.5 \pm 1.2$ & $48.2 \pm 1.4$ & $45.5 \pm 1.3$ & $44.7 \pm 1.3^{3 \mathrm{ab}}$ \\
\hline & 14 & $40 \pm 1.2$ & $47.7 \pm 1.4$ & $45.0 \pm 1.3$ & $44.3 \pm 1.3^{\mathrm{ab}}$ \\
\hline & 21 & $39.4 \pm 1.1$ & $47.2 \pm 1.4$ & $44.6 \pm 1.3$ & $43.7 \pm 1.3^{b}$ \\
\hline & 28 & $38.9 \pm 1.1$ & $46.5 \pm 1.4$ & $44 \pm 1.3$ & $43.2 \pm 1.2^{b}$ \\
\hline & Means & $40 \pm 1.2^{\mathrm{b}}$ & $47.7 \pm 1.4^{\mathrm{a}}$ & $45 \pm 1.3^{\mathrm{ab}}$ & \\
\hline \multirow{6}{*}{ Chroma } & 0 & $45.8 \pm 1.3$ & $53 \pm 1.5$ & $50.2 \pm 1.5$ & $49.7 \pm 1.4^{a}$ \\
\hline & 7 & $45.4 \pm 1.3$ & $52.5 \pm 1.5$ & $49.7 \pm 1.4$ & $49.2 \pm 1.4^{a}$ \\
\hline & 14 & $44.8 \pm 1.3$ & $51.9 \pm 1.5$ & $49.3 \pm 1.4$ & $48.7 \pm 1.4^{\mathrm{ab}}$ \\
\hline & 21 & $44.2 \pm 1.3$ & $51.3 \pm 1.5$ & $48.8 \pm 1.4$ & $48.1 \pm 1.4^{\mathrm{ab}}$ \\
\hline & 28 & $43.6 \pm 1.2$ & $50.6 \pm 1.5$ & $48.2 \pm 1.4$ & $47.5 \pm 1.4^{b}$ \\
\hline & Means & $44.7 \pm 1.3^{b}$ & $51.9 \pm 1.5^{\mathrm{a}}$ & $49.2 \pm 1.4^{\mathrm{ab}}$ & \\
\hline \multirow{6}{*}{ Hue angle } & 0 & $63.3 \pm 1.9$ & $66.9 \pm 2$ & $66.1 \pm 1.9$ & $65.4 \pm 1.9$ \\
\hline & 7 & $63.3 \pm 1.8$ & $66.8 \pm 2$ & $66 \pm 1.9$ & $65.4 \pm 1.9$ \\
\hline & 14 & $63.3 \pm 1.9$ & $66.8 \pm 2$ & $66 \pm 1.9$ & $65.4 \pm 1.9$ \\
\hline & 21 & $63.2 \pm 1.8$ & $66.8 \pm 2.1$ & $65.9 \pm 1.9$ & $65.3 \pm 1.9$ \\
\hline & 28 & $63.2 \pm 1.8$ & $66.8 \pm 2.1$ & $66 \pm 1.9$ & $65.3 \pm 1.8$ \\
\hline & Means & $63.3 \pm 1.9^{b}$ & $66.8 \pm 2.1^{a}$ & $66 \pm 1.9^{a}$ & \\
\hline
\end{tabular}

$\mathrm{T}_{0}=$ Control (without garlic extract)

$\mathrm{T}_{1}=$ Garlic chicken bites with garlic extract (CSE)

$\mathrm{T}_{2}=$ Garlic chicken bites with garlic extract (SFE)

*Statistical significance determined (alphabetic) using a two-way ANOVA with Tukey Multiple Comparison test compared to treatment and storage days with $* \mathrm{P}<0.05$.

the $L^{*}$ value was initially rapid but slowed down as frying time increased. The values range from 52 to 59 at 300 seconds of frying depending on the different oil types used. The $\mathrm{a}^{*}$ values also increased significantly with frying time and the degree of hydrogenation. Results also revealed that lower degrees of hydrogenation (0,20 and 60\%) causes lower redness values than hydrogenation at 40,80 and $100 \%$. The $b^{*}$ values of chicken nuggets increased sharply within the first 60 seconds of frying, but tended to equilibrate after frying for 240 seconds. Chroma index was used to describe color saturation of chicken nuggets. The index also improved with increasing the frying 
time. Chroma analysis indicated that both the degrees of hydrogenation and frying time have significant effect on chroma of fried chicken nuggets.

One of the researchers group, Verma et al. [26] evaluated the influence of sodium chloride replacement and apple pulp inclusion on the physicochemical, textural and sensory properties of low fat chicken nuggets. They concluded that $\mathrm{a}^{*}$ value of control $(2.8 \pm 0.5)$ and low pulp treatment $(2.9 \pm$ $0.6)$ was comparable. However, incorporation of apple pulp at higher levels significantly increased $a^{*}(3.3 \pm 0.8)$ of nuggets. The $b^{*}$ of treatment products was considerably higher when compared to control. Similar trend was observed in case of hue and chroma values. A significant increase in redness value of "Bologna Sausages" incorporated with 7.5 and $10 \mathrm{~g} / 100 \mathrm{~g}$ cooked lemon albedo was reported by Fernandez-Gines et al. [27]. Oil temperature and sample thickness are the process parameters that affect the color characteristics significantly during frying. The color change phenomenon gets more intense at higher temperatures and smaller sample thickness $[28,29]$.

Earlier, Sallam et al. [14] concluded that storage time has non-substantial impact on the intensity of garlic flavor, tenderness or the acceptability scores of cooked chicken sausages. The intensity of garlic flavor, tenderness and overall acceptability of chicken sausage as affected by different equivalent concentrations of fresh garlic, garlic powder and garlic oil during storage. Fresh garlic sausages possess high overall acceptability while garlic oil has high tenderness score. All the garlic formulations were having more garlic flavor than the control: Chicken sausage containing fresh garlic had a significant strong flavor than that of garlic powder and garlic oil.

Texture: For texture profile analysis (TPA), the recorded hardness of the samples illustrated that the bites became harder with the addition of garlic extract (CSE) requiring increased compression force. However, addition of garlic extract (SFE) did not affect bites hardness to great extent and force measured for $\mathrm{T}_{2}$ was closer to control. The hardness of chicken bites showed significant results as a function of treatments

Table 3: Effect of treatments and storage on texture ( $\mathrm{kg}$ force) of garlic chicken bites

\begin{tabular}{|l|l|l|l|l|}
\hline \multirow{2}{*}{$\begin{array}{l}\text { Storage } \\
\text { (days) }\end{array}$} & \multicolumn{2}{|l|}{ Treatments } & \multicolumn{2}{|l|}{ Means } \\
\cline { 2 - 5 } & $\mathbf{T}_{\mathbf{0}}$ & $\mathbf{T}_{\mathbf{1}}$ & $\mathbf{T}_{\mathbf{2}}$ & \\
\hline $\mathbf{0}$ & $0.88 \pm 0.02$ & $0.92 \pm 0.02$ & $0.85 \pm 0.02$ & $0.88 \pm 0.02^{\mathrm{a}}$ \\
\hline $\mathbf{7}$ & $0.87 \pm 0.02$ & $0.91 \pm 0.02$ & $0.83 \pm 0.02$ & $0.87 \pm 0.02^{\mathrm{a}}$ \\
\hline $\mathbf{1 4}$ & $0.86 \pm 0.02$ & $0.89 \pm 0.02$ & $0.82 \pm 0.02$ & $0.85 \pm 0.02^{\mathrm{ab}}$ \\
\hline $\mathbf{2 1}$ & $0.84 \pm 0.02$ & $0.88 \pm 0.02$ & $0.82 \pm 0.02$ & $0.84 \pm 0.02^{\mathrm{ab}}$ \\
\hline $\mathbf{2 8}$ & $0.82 \pm 0.02$ & $0.86 \pm 0.02$ & $0.80 \pm 0.02$ & $0.82 \pm 0.02^{\mathrm{b}}$ \\
\hline Means & $0.85 \pm 0.02^{\mathrm{b}}$ & $0.89 \pm 0.02^{\mathrm{a}}$ & $0.82 \pm 0.02^{\mathrm{c}}$ & \\
\hline
\end{tabular}

$\mathrm{T}_{0}=$ Control (without garlic extract)

$\mathrm{T}_{1}=$ Garlic chicken bites with garlic extract (CSE)

$\mathrm{T}_{2}=$ Garlic chicken bites with garlic extract (SFE)

*Statistical significance determined (alphabetic) using a two-way ANOVA with Tukey Multiple Comparison test compared to treatment and storage days with $* \mathrm{P}<0.05$ and storage interval with a non-significant interaction effect. Means for bites TPA (Table 3) indicated higher value for $\mathrm{T}_{2}$ $(0.89 \pm 0.02 \mathrm{~kg}$ force $)$, followed by $\mathrm{T}_{0}(0.85 \pm 0.02 \mathrm{~kg}$ force $)$ and $\mathrm{T}_{1}(0.82 \pm 0.02 \mathrm{~kg}$ force $)$. During the storage period, momentous variations were observed for the hardness values of different samples that decreased from $0.88 \pm 0.02 \mathrm{~kg}$ force to $0.82 \pm 0.02 \mathrm{~kg}$ force.

Similar findings were obtained by Mendoza et al. [30], as observed decreasing trend in hardness and chewiness values of low fat dry fermented sausages incorporated with inulin as a fat substitute and source of soluble dietetic fiber. It was observed that the treated samples had significantly higher $\mathrm{pH}$, shear force, moisture and protein contents, sensory attributes and lower free fatty acids content in comparison to control aerobically packed samples [31].

Another important quality attribute of fried products is crispiness. The formulation of crispy crust depends on both the product and on process conditions. Ngadi et al. [18] observed that thawed raw chicken nuggets are usually mushy and soft textured. Upon frying, the texture changes and becomes tough. Moreover, nuggets texture gets harder in first $60 \mathrm{sec}$. During frying, it increases in protein denaturation and loss in moisture resulted in increased hardness and crispiness of the finished product.

\section{Total phenolic content}

Statistical analysis regarding total phenolic content (TPC) of garlic chicken bites depicted significant differences due to treatment and storage period. Instead, the interaction effect was non-momentous. Means regarding TPC showed that maximum value of $71 \pm 3.2 \mathrm{mg}$ GAE $/ 100 \mathrm{~g}$ was recorded in bites containing garlic extract (SFE) $\left(\mathrm{T}_{2}\right)$ while the value of TPC was $67.3 \pm 2.5$ and $60.9 \pm 3.7 \mathrm{mg} \mathrm{GAE} / 100 \mathrm{~g}$ for garlic chicken bites having garlic extract $(\mathrm{CSE})\left(\mathrm{T}_{1}\right)$ and control $\left(\mathrm{T}_{0}\right)$, respectively. Storage affected the TPC slightly and its value decreased from $68.8 \pm 2.5$ to $63.5 \pm 2.9 \mathrm{mg} \mathrm{GAE} / 100 \mathrm{~g}$ during the 28 days storage period (Table 4). In current work, the total

Table 4: Effect of treatments and storage on total phenolics (mg GAE/100 g) of garlic chicken bites

\begin{tabular}{|l|l|l|l|l|}
\hline \multirow{2}{*}{$\begin{array}{l}\text { Storage } \\
\text { (days) }\end{array}$} & \multicolumn{2}{|l|}{ Treatments } & \multirow{2}{*}{ Means } \\
\cline { 2 - 4 } & $\mathbf{T}_{\mathbf{0}}$ & $\mathbf{T}_{\mathbf{1}}$ & $\mathbf{T}_{\mathbf{2}}$ & \\
\hline $\mathbf{0}$ & $63.8 \pm 2.7$ & $69.4 \pm 3.8$ & $73.2 \pm 3.7$ & $68.8 \pm 2.5^{\mathrm{a}}$ \\
\hline $\mathbf{7}$ & $62.2 \pm 2.4$ & $68.2 \pm 2.7$ & $72.1 \pm 2.7$ & $67.5 \pm 2.8^{\mathrm{ab}}$ \\
\hline $\mathbf{1 4}$ & $61.7 \pm 2.5$ & $67.7 \pm 3.4$ & $71.2 \pm 3.6$ & $66.9 \pm 2.4^{\mathrm{ab}}$ \\
\hline $\mathbf{2 1}$ & $59.8 \pm 2.2$ & $66.3 \pm 2.5$ & $69.6 \pm 3.8$ & $65.2 \pm 2.8^{\mathrm{b}}$ \\
\hline $\mathbf{2 8}$ & $57 \pm 2.1$ & $64.9 \pm 3.2$ & $68.7 \pm 2.3$ & $63.5 \pm 2.9^{\mathrm{bc}}$ \\
\hline Means & $60.9 \pm 3.7^{\mathrm{c}}$ & $67.3 \pm 2.5^{\mathrm{b}}$ & $71 \pm 3.2^{\mathrm{a}}$ & \\
\hline
\end{tabular}

$\mathrm{T}_{0}=$ Control (without garlic extract)

$\mathrm{T}_{1}=$ Garlic chicken bites with garlic extract (CSE)

$\mathrm{T}_{2}=$ Garlic chicken bites with garlic extract (SFE)

*Statistical significance determined (alphabetic) using a two-way ANOVA with Tukey Multiple Comparison test compared to treatment and storage days with $* \mathrm{P}<0.05$. 
phenolic content increased in conventional and supercritical extracts enriched chicken bites as compared to control.

Phenolics constitute, a major group of compounds acting as primary antioxidants or free radical terminators/scavengers. Estimation of total phenolic content is important factor to evaluate the amount of antioxidants [32]. Banerjee et al. [23] concluded that total phenolics in $5 \mathrm{mg}$ broccoli powder was significantly higher than $0.1 \mathrm{mg} / \mathrm{g}$ BHT, but less as compared to $0.15 \mathrm{mg} / \mathrm{g}$. It was indicated that incorporation of broccoli powder extracts @ 1 and $2 \%$ level or 0.1 and $0.2 \%$ broccoli powder showed significantly increased phenolic content in goat meat nuggets that serve as a source of natural antioxidants. Fried food items are widely consumed across the world for their taste and convenience. Addition of bioactive or functional ingredients in these fried foods can result in the formulation of a better-accepted dietary product such as chicken bites formulated in our project.

\section{Conclusion}

Garlic extract contains different phytochemicals that can be fortified in different food products like chicken bites to improve stability and hedonic attributes. These enriched garlic chicken bites are of higher nutritional significance owing to rich in phenolic compounds that contain health promoting perspectives. Furthermore, advancement in extraction and processing technologies can be helpful to introduce more functional and nutraceutical food formulations which are chemically more stable, acceptable and have ability to prevent different metabolic syndromes.

\section{Acknowledgements}

The authors are thankful to Functional and Nutraceutical Food Research Section, National Institute of Food Science and Technology, University of Agriculture, Faisalabad, Pakistan. This research was partially supported by Higher Education Commission, Pakistan under Pak-US Science and Technology Cooperation Program Phase IV with project entitled "Establishment of Functional and Nutraceutical Food Research Section at the National Institute of Food Science and Technology, University of Agriculture, Faisalabad, Pakistan”.

\section{Conflict of Interest}

The authors have no conflicts of interest.

\section{References}

1. Raza A, Shabbir M, Khan M, Suleria H, Sultan S. 2015. Effect of thermal treatments on the formation of heterocyclic aromatic amines in various meats. $J$ Food Process Preserv 39(4): 376-383. https://doi. org/10.1111/jfpp. 12242

2. Shabbir MA, Raza A, Anjum FM, Khan MR, Suleria HA. 2015. Effect of thermal treatment on meat proteins with special reference to heterocyclic aromatic amines (HAAs). Crit Rev Food Sci Nutr 55(1): 82-93. https://doi.org/10.1080/10408398.2011.647122

3. Rasul Suleria HA, Sadiq Butt M, Muhammad Anjum F, Saeed F, Batool R, et al. 2012. Aqueous garlic extract and its phytochemical profile; special reference to antioxidant status. Int J Food Sci Nutr 63(4): 431-439. https://doi.org/10.3109/09637486.2011.634786
4. Suleria HAR, Butt MS, Khalid N, Sultan S, Raza A, et al. 2015. Garlic (Allium sativum): diet based therapy of $21^{\text {st }}$ century-a review. Asian Pacific J Trop Dis 5(4): 271-278. https://doi.org/10.1016/S22221808(14)60782-9

5. ETOH T, Watanabe H, Iwai S. 2001. RAPD variation of garlic clones in the center of origin and the westernmost area of distribution. Mem Fac Agr Kogoshima Univ 37: 21-27.

6. Li Y, Xu S-Y, Sun D-W. 2007. Preparation of garlic powder with high allicin content by using combined microwave-vacuum and vacuum drying as well as microencapsulation. J Food Eng 83(1): 76-83. https:// doi.org/10.1016/j.jfoodeng.2007.02.057

7. Suleria H, Butt M, Anjum F, Ashraf M, Qayyum M, et al.2013. Aqueous garlic extract attenuates hypercholesterolemic and hyperglycemic perspectives; rabbit experimental modeling. Journal of Medicinal Plants Research 7(23): 1709-1717.

8. Suleria H, Khalid N, Sultan S, Raza A, Muhammad A, et al. 2015. Functional and nutraceutical bread prepared by using aqueous garlic extract. Internet Journal of Food Safety 17: 10-20.

9. Rahman MS. 2007. Allicin and other functional active components in garlic: health benefits and bioavailability. Int J Food Prop 10(2): 245-268. https://doi.org/10.1080/10942910601113327

10. Tsai CW, Chen HW, Sheen LY, Lii CK. 2012. Garlic: health benefits and actions. BioMedicine 2(1): 17-29. https://doi.org/10.1016/j. biomed.2011.12.002

11. Suleria HA, Butt MS, Anjum FM, Saeed F, Khalid N. 2015. Onion: nature protection against physiological threats. Crit Rev Food Sci Nutr 55(1): 50-66. https://doi.org/10.1080/10408398.2011.646364

12. Yang HS, Lee EJ, Moon SH, Paik HD, Nam K et al. 2011. Effect of garlic, onion, and their combination on the quality and sensory characteristics of irradiated raw ground beef. Meat Sci 89(2): 202-208. https://doi.org/10.1016/j.meatsci.2011.04.020

13. Fawad SA, Khalid N, Asghar W, Rasul Suleria HA. 2012. In vitro comparative study of Bougainvillea spectabilis "stand" leaves and Bougainvillea variegata leaves in terms of phytochemicals and antimicrobial activity. Chin J Nat Med 10(6): 441-447. https://doi. org/10.1016/S1875-5364(12)60085-5

14. Sallam KI, Ishioroshi M, Samejima K. 2004. Antioxidant and antimicrobial effects of garlic in chicken sausage. Lebenson Wiss Technol 37(8): 849-855. https://doi.org/10.1016/j.lwt.2004.04.001

15. Shi J. 2006. Functional food ingredients and nutraceuticals: processing technologies. CRC Press.

16. Iqbal S, Bhanger M. 2007. Stabilization of sunflower oil by garlic extract during accelerated storage. Food Chem 100(1): 246-254. https:// doi.org/10.1016/j.foodchem.2005.09.049

17. del Valle JM, Glatzel V, Martínez JL. 2012. Supercritical $\mathrm{CO}_{2}$ extraction of allicin from garlic flakes: screening and kinetic studies. Food Res Int 45(1): 216-224. https://doi.org/10.1016/j.foodres.2011.10.021

18. Ngadi M, Li Y, Oluka S. 2007. Quality changes in chicken nuggets fried in oils with different degrees of hydrogenatation. LWT-Food Science and Technology 40(10): 1784-1791. https://doi.org/10.1016/j. lwt.2007.01.004

19. Saeed F, Arshad M, Pasha I, Suleria H, Arshad M, et al. 2015. Effect of arabinoxylan and arabinogalactan on textural attributes of bread. J Food Process Preserv 39(6): 1070-1088. https://doi.org/10.1111/jfpp.12322

20. Asimi OA, Sahu N, Pal A. 2013. Antioxidant activity and antimicrobial property of some Indian spices. International Journal of Scientific and Research Publication 3(3): 1-8.

21. Kuehl RO. 2000. Design of experiments: statistical principles of research design and analysis.

22. Teruel MR, Garrido MD, Espinosa MC, Linares MB. 2015. Effect of different format-solvent rosemary extracts (Rosmarinus officinalis) on frozen chicken nuggets quality. Food Chem 172: 40-46. https://doi. org/10.1016/j.foodchem.2014.09.018 
23. Banerjee R, Verma AK, Das AK, Rajkumar V, Shewalkar A, et al. 2012. Antioxidant effects of broccoli powder extract in goat meat nuggets. Meat Sci 91(2): 179-184.https://doi.org/10.1016/j.meatsci.2012.01.016

24. Awan KA, Butt MS, Awan JA, Zahoor T. 2015. Sensory profile of conventional and supercritical garlic extract-nutrified chicken bites. Pakistan Journal of Food Sciences 25: 92-97.

25. Naveena B, Sen A, Vaithiyanathan S, Babji Y, Kondaiah N. 2008. Comparative efficacy of pomegranate juice, pomegranate rind powder extract and BHT as antioxidants in cooked chicken patties. Meat Sci 80(4): 1304-1308. https://doi.org/10.1016/j.meatsci.2008.06.005

26. Verma AK, Sharma B, Banerjee R. 2010. Effect of sodium chloride replacement and apple pulp inclusion on the physico-chemical, textural and sensory properties of low fat chicken nuggets. LWT-Food Science and Technology 43(4): 715-719. https://doi.org/10.1016/j.lwt.2009.12.006

27. Fernández-Ginés J, Fernández-López J, Sayas-Barbera E, Sendra E, Perez-Alvarez J. 2004. Lemon albedo as a new source of dietary fiber: application to bologna sausages. Meat Sci 67(1): 7-13. https://doi. org/10.1016/j.meatsci.2003.08.017
28. Krokida M, Oreopoulou V, Maroulis Z, Marinos-Kouris D. 2001. Deep fat frying of potato strips-quality issues. Journal of Drying Technology 19(5): 879-935. https://doi.org/10.1081/DRT-100103773

29. Krokida M, Oreopoulou V, Maroulis Z, Marinos-Kouris D. 2001. Colour changes during deep fat frying. J Food Eng 48(3): 219-225. https://doi.org/10.1016/S0260-8774(00)00161-8

30. Mendoza E, Garcia M, Casas C, Selgas M. 2001. Inulin as fat substitute in low fat, dry fermented sausages. Meat Sci 57(4): 387-393. https://doi. org/10.1016/S0309-1740(00)00116-9

31. Sahoo J, Anjaneyulu A. 1997. Effect of natural antioxidants and vacuum packaging on the quality of buffalo meat nuggets during refrigerated storage. Meat Sci 47(3-4): 223-230. https://doi.org/10.1016/S03091740(97)00053-3

32. Park M-H, Kim J-G. 2015. Low-dose UV-C irradiation reduces the microbial population and preserves antioxidant levels in peeled garlic (Allium sativum L.) during storage. Postharvest Biology and Technology 100: 109-112. https://doi.org/10.1016/j.postharvbio.2014.09.013 